\title{
Comparison of Mammography and Ultrasonography for Early Detection of Breast Cancer - A Systematic Review
}

\author{
SAMINA MAHMOOD ${ }^{1}$, MUHAMMAD NAWAZ ANJUM ${ }^{2}$, FAIZA FAROOQ ${ }^{3}$, SYED AMIR GILANI ${ }^{4}$, MEHREEN FATIMA ${ }^{5}$, \\ SHAKILA ANDLIB ${ }^{6}$, HAFIZA SOBIA RAMZAN ${ }^{7}$ \\ ${ }^{1}$ Fatima Memorial Hospital Lahore \\ ${ }^{2}$ Head of Department Radiology Research Section, University of Lahore \\ 3,4,5,7 University of Lahore Teaching Hospital \\ ${ }^{6}$ District Headquarters Hospital Sahiwal \\ Correspondence to Dr. Samina Mahmood, Email: drsamina3@gmail.com, Cell: +92 3314844208
}

\begin{abstract}
Aim: This systematic review is specifically aimed to compare mammography and ultrasonography in early detection of breast cancer. For this systematic review, major purpose is to compare both screening methods and also analyze the performance of supplemental ultrasonography for early detection of breast cancer.

Methodology: For this systematic review, total 23 studies are included which follow the Preferred Reporting Items for Systematic Reviews and Meta-Analysis (PRISMA) guidelines. Electronic articles from year 2007 to from year 2017 on PUB Med, online Willey library, and Science Direct site were searched by using keywords related to sonographic and mammography imaging for breast cancer.

Results: Out of 23 studies, 12 studies are conducted on women with dense breasts. Twenty studies performed their imaging with hand held ultrasound (HHUS). Out of twenty-three studies, sixteen studies followed BI-RADS procedures. In eleven studies that used joint methods, it was observed that mammography (MAM) has $65 \%$ whereas ultrasound (US) has $68 \%$ efficiency for early detection of breast cancer. $88 \%$ area under a cover (AUCs) among MAM and $98 \%$ among US imaging was observed. No major difference was found in sensitivity and specificity of both techniques.

Conclusion: Study concludes that Ultrasound is more efficient to diagnose factors suggestive of breast cancer that cannot be detected on mammography. It also has the potential to evaluate cancer among dense breast women but unfortunately in some cases, it may cause a high recall rate.

Keywords: Breast, Cancer, Mammography, Ultrasonography, Screening.
\end{abstract}

\section{INTRODUCTION}

All around the world, cancer holds a significant value of consideration due to its high morbidity and mortality ratio. In 2016, statistics revealed 17.2 million cancer cases along with 8.9 million deaths reported in the same year. Among women breast cancer holds a significant place in mortality and disability ${ }^{1}$. Considerably, 535, 000 deaths from breast cancer are reported every year in both developed and developing countries. In recent years, a high prevalence of breast cancer is majorly observed in underdeveloped countries $^{2}$. Aging and bad lifestyles including smoking, poor diet, physical inactivity are triggering factors for breast cancer ${ }^{3}$. In developing countries, there is a great urge to initiate preventing measurements especially cancer screening.

Since 1970 mammography is used as a primary screening method for breast cancer. Due to less availability of mammography equipment, it is not widely available in under developed countries so they used Ultrasonography as an alternative method of screening ${ }^{3}$. Women having dense breast has a low sensitivity to mammography ${ }^{4}$. These women may have a high risk of breast cancer as compared to less dense breasts $^{5}$. In Denmark and Netherlands, researchers claim that every one of three women suffering from cancer is diagnosed with breast cancer $^{6,7}$. In recent years supplemental ultrasonography is considered the best screening method to detect more

Received on 03-03-2021

Accepted on 23-06-2021 variations of breast cancer as compared to primary mammography-11. This systematic review is specifically aimed to compare mammography and ultrasonography for early detection of breast cancer. Major purpose of this systematic review is, to compare both screening methods and also analyze the performance of supplemental ultrasonography for breast cancer patients.

\section{METHODOLOGY}

Search Strategy: For this study, Preferred Reporting Items guideline for systematic reviews and meta-analyses (PRISMA) 12 was followed. Electronic articles from year 2007 to 2017 on PUB Med, online Willey library, and Science Direct site were searched. Keywords like Diagnostic Imaging" OR "Diagnostic Radiology" OR "Medical Imaging" OR "primary mammography" OR "Mammography Vs sonography" OR "breast mammography a good source of detection", Supplemental sonography for breast cancer detection", OR "breast imaging" OR "Primary sonography for breast cancer detection" OR "breast imaging guidelines" were used to search relevant articles. It was assured that all the data has information such as cancer detection rate (including carcinoma in situ and invasive cancer but not high-risk precancerous lesion), recall rate, size of the tumor, biopsy rate. With the help of keywords, the title, abstract aims, and objectives were analyzed to extract the relevant data.

Inclusion criteria: Articles and case studies with complete demographic information and type of study along with the 
recall rate, biopsy rate of patients were included for this research.

Exclusion Criteria: Information in the form of posters, case studies without imaging, letters to editors, and articles with copied information was excluded from this study. Articles which were written in other than English language were not included for this research. On the behalf of keywords we found nine hundred sixty-two articles.

Fig 1: Inclusion Criteria

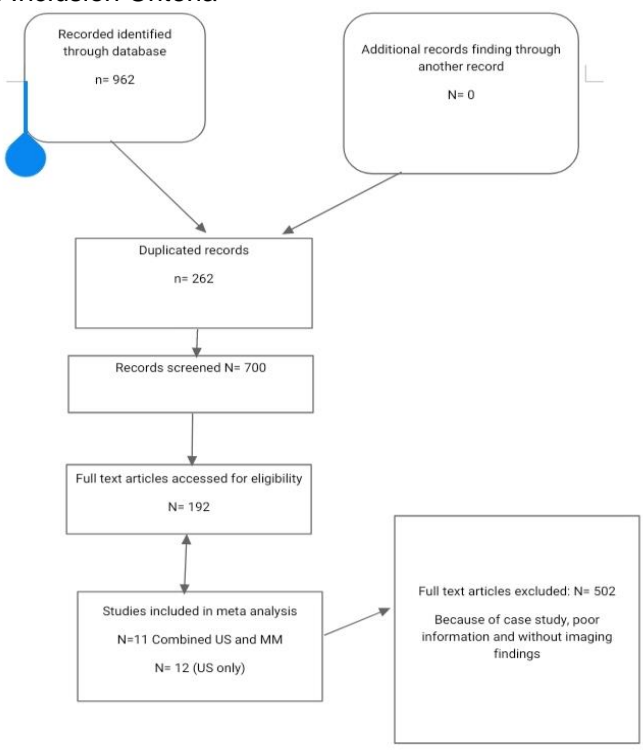

The evaluation of selected data was further done into two phases. Firstly, the data based on abstract and title was selected. Secondly, the inner text of articles was examined and articles that fulfilled the inclusion criteria of this study were sorted out. At the initial stage of data collection, nine hundred and sixty-two articles were found with selected keywords. In the first screening, 262 duplicate articles were excluded. Further screening of rest of 700 articles was done and 502 articles with poor information on mammography and sonographic imaging were omitted. 192 articles were further gone through the screening process. At the last stage, 23 (11 combination of mammography and primary ultrasonography and 12 on supplemental ultrasonography) articles were found that fulfilled the inclusion criteria and had adequate data aimed at the topic.

Demographic information of patients like mean age and range, the sample size is kept in tabular form. Findings regarding sensitivity and specificity of all selected researches were observed.

\section{RESULTS}

Out of 23 studies, 12 studies were conducted on women with dense breasts. Twenty studies performed their imaging with HHUS. Out of twenty-three studies, sixteen studies followed BI-RADS procedures. In eleven studies that used joint methods, it was observed that MAM had $65 \%$ whereas the US has $68 \%$ efficiency for early detection of breast cancer whereas $88 \%$ AUCs among MAM and $98 \%$ among US imaging was observed. No major difference in sensitivity and specificity (as mentioned in the forest plot) was found.

Table 1: Demographic Characteristics of selected studies

\begin{tabular}{|c|c|c|c|c|c|}
\hline Author & Year & Country & Study type & Study sample & Mean Age \\
\hline Honjo $^{13}$ & 2007 & Japan & Prospective & 3453 & Not mentioned \\
\hline Tagliafico $^{14}$ & 2016 & Italy & Prospective & 3231 & 51 \\
\hline Weinstein $^{15}$ & 2009 & United States & Prospective & 609 & 49 \\
\hline $\mathrm{Kim}^{16}$ & 2016 & South Korea & Retrospective & 3171 & Not mentioned \\
\hline Venturini $^{17}$ & 2013 & Italy & Prospective & 1666 & 46 \\
\hline Weigert $^{18}$ & 2015 & United States & Retrospective & 10282 & Not mentioned \\
\hline Wilczek $^{19}$ & 2016 & Sweden & Prospective & 1668 & 50 \\
\hline Hwang $^{20}$ & 2015 & South Korea & Retrospective & 1727 & 50 \\
\hline Kelly ${ }^{21}$ & 2010 & United States & Prospective & 4419 & 53 \\
\hline Moon $^{22}$ & 2015 & South Korea & Retrospective & 2005 & 53 \\
\hline Huang $^{23}$ & 2012 & China & Prospective & 3028 & 46 \\
\hline Parris $^{24}$ & 2013 & United States & Retrospective & 5519 & 52 \\
\hline Brem $^{25}$ & 2015 & United States & Prospective & 15318 & 53 \\
\hline Girardi $^{26}$ & 2013 & Italy & Retrospective & 22131 & 51 \\
\hline Shen $^{27}$ & 2015 & China & Prospective & 4135 & 46 \\
\hline Leong $^{28}$ & 2012 & Singapore & Retrospective & 106 & 45 \\
\hline Berg $^{11}$ & 2016 & United States & Prospective & 2662 & 55 \\
\hline Hooley $^{29}$ & 2012 & United States & Retrospective & 648 & 52 \\
\hline Ohuchi $^{10}$ & 2016 & Japan & Prospective & 36752 & 44 \\
\hline Corsetti $^{30}$ & 2011 & Italy & Retrospective & 3356 & Not mentioned \\
\hline Dong $^{9}$ & 2017 & United States & Prospective & 32918 & 52 \\
\hline Youk $^{31}$ & 2011 & South Korea & Retrospective & 446 & 48 \\
\hline Brancato $^{32}$ & 2007 & Italy & Prospective & 5227 & 52 \\
\hline
\end{tabular}

Table 2: Baseline Characteristics of selected studies

\begin{tabular}{|l|l|l|l|l|}
\hline Author & Study months & Quality Assessment & Type of imaging & Equipment \\
\hline Honjo & $\geq 18$ & Fair & US +MM & HHUS \\
\hline Tagliafico & $<12$ & Fair & US & HHUS \\
\hline Weinstein & 12 & Fair & US + MM & HHUS \\
\hline Kim & 12 & Fair & US & HHUS \\
\hline Venturini & 6 & Fair & US + MM & HHUS \\
\hline Weigert & Fair & US & HHUS \\
\hline
\end{tabular}




\begin{tabular}{|l|l|l|l|l|}
\hline Wilczek & 24 & Fair & US +MM & ABUS \\
\hline Hwang & 12 & Fair & US & HHUS \\
\hline Kelly & 12 & High & US + MM & ABUS \\
\hline Moon & 24 & Fair & US & HHUS \\
\hline Huang & High & US +MM & HHUS \\
\hline Parris & Not mentioned & Fair & US & HHUS \\
\hline Brem & High & US +MM & ABUS \\
\hline Girardi & Nair & US & HHUS \\
\hline Shen & Not mentioned & High & US +MM & HHUS \\
\hline Leong & 12 & Fair & US & HHUS \\
\hline Berg & High & US + MM & HHUS \\
\hline Hooley & $>12$ & Fair & US & HHUS \\
\hline Ohuchi & $>15$ & High & US +MM & HHUS \\
\hline Corsetti & 12 & Fair & US & HHUS \\
\hline Dong & 12 & High & US +MM & HHUS \\
\hline Youk & 12 & Fair & US & HHUS \\
\hline Brancato & 24 & Fair & US & HHUS \\
\hline
\end{tabular}

Table 3: Sensitivity and Specificity rate of Mammography and Ultrasonography

\begin{tabular}{|c|c|c|c|c|}
\hline Author & Sensitivity Rate of US & Sensitivity rate of MM & Specificity rate of US & Specificity rate of MM \\
\hline Honjo & $0.54(0.26-0.80)$ & $0.62(0.32-0.85)$ & $0.96(0.95-0.96)$ & $0.92(0.91-0.93)$ \\
\hline Tagliafico & $0.96(0.77-1.00)$ & & $0.98(0.97-0.98)$ & \\
\hline Weinstein & $0.15(0.04-0.39)$ & $0.35(0.16-0.59)$ & $0.93(0.91-0.95)$ & $0.93(0.91-0.95)$ \\
\hline Kim & $1.00(0.63-1.00)$ & & $0.74(0.72-0.76)$ & \\
\hline Venturini & $0.14(0.03-0.44)$ & $0.86(0.56-0.97)$ & $0.99(0.98-1.00)$ & $0.94(0.93-0.95)$ \\
\hline Weigert & $0.62(0.45-0.76)$ & & $0.96(0.96-0.96)$ & \\
\hline Wilczek & $1.00(0.68-1.00)$ & $0.64(0.32-0.88)$ & $0.99(0.98-0.99)$ & $0.99(0.98-0.99)$ \\
\hline Hwang & $0.89(0.51-0.99)$ & & $0.95(0.93-0.96)$ & \\
\hline Kelly & $0.67(0.53-0.78)$ & $0.40(0.28-0.54)$ & $0.99(0.98-0.99)$ & $0.99(0.99-0.99)$ \\
\hline Moon & $1.00(0.40-1.00)$ & & $0.69(0.67-0.71)$ & \\
\hline Huang & $0.73(0.54-0.86)$ & $0.85(0.67-0.94)$ & $0.99(0.99-1.00)$ & $0.98(0.98-0.99)$ \\
\hline Parris & $1.00(0.66-1.00)$ & & $0.97(0.96-0.97)$ & \\
\hline Brem & $0.85(0.77-0.91)$ & $0.73(0.64-0.81)$ & $0.83(0.82-0.83)$ & $0.85(0.85-0.86)$ \\
\hline Girardi & $1.00(0.89-1.00)$ & & $0.98(0.98-0.98)$ & \\
\hline Shen & $1.00(0.73-1.00)$ & $0.57(0.30-0.81)$ & $1.00(1.00-1.00)$ & $1.00(1.00-1.00)$ \\
\hline Leong & $1.00(0.20-1.00)$ & & $0.91(0.85-0.95)$ & \\
\hline Berg & $0.52(0.43-0.62)$ & $0.53(0.43-0.63)$ & $0.86(0.85-0.87)$ & $0.90(0.90-0.91)$ \\
\hline Hooley & $1.00(0.31-1.00)$ & & $0.77(0.73-0.80)$ & \\
\hline Ohuchi & $0.71(0.64-0.77)$ & $0.58(0.51-0.65)$ & $0.94(0.93-0.94)$ & $0.94(0.93-0.94)$ \\
\hline Corsetti & $0.80(0.64-0.90)$ & & $0.95(0.94-0.95)$ & \\
\hline Dong & $0.62(0.51-0.71)$ & $0.85(0.76-0.91)$ & $0.99(0.99-0.99)$ & $0.98(0.98-0.98)$ \\
\hline Youk & $0.91(0.57-1.00)$ & & $0.91(0.87-0.93)$ & \\
\hline Brancato & $1.00(0.20-1.00)$ & & $0.98(0.98-0.98)$ & \\
\hline
\end{tabular}

\begin{tabular}{|c|c|c|c|c|c|c|}
\hline Author & $\begin{array}{l}\text { Cancer detected } \\
\text { ratio by US }\end{array}$ & $\begin{array}{l}\text { Cancer detected } \\
\text { ratio by MM }\end{array}$ & $\begin{array}{l}\text { Proportion of invasive } \\
\text { cancer by US }\end{array}$ & $\begin{array}{l}\text { Proportion of invasive } \\
\text { cancer by MM }\end{array}$ & $\begin{array}{l}\text { Cancer recall } \\
\text { ratio by US }\end{array}$ & $\begin{array}{l}\text { Cancer recall } \\
\text { ratio by MM }\end{array}$ \\
\hline Honjo & $2.0(0.9-4.3)$ & $2.3(1.1-4.6)$ & $1.000(0.59,1.000)$ & $0.62(0.244,0.91)$ & $4.7(4.0-5.4)$ & $7.9(7.0-8.8)$ \\
\hline Tagliafico & $7.1(4.6-10.8)$ & & $0.0071(0.0045,0.010)$ & & $2.7(2.2-3.4)$ & \\
\hline Weinstein & $5.3(1.4-16.7)$ & $12.3(5.4-26.3)$ & $1.000(0.29,1.000)$ & $0.42(0.09,0.81)$ & $6.9(5.0-9.4)$ & $6.9(5.1-9.3)$ \\
\hline Kim & $2.8(1.4-5.6)$ & & $0.028(0.0013,0.054)$ & & $26.2(24.7-27.8)$ & \\
\hline Venturini & $2.4(0.4-9.6)$ & $7.2(3.9-12.9)$ & $1.00(0.15,1.000)$ & $0.666(0.348,0.99)$ & $10.4(8.5-12.7)$ & $4.6(3.6-5.7)$ \\
\hline Weigert & $2.3(1.5-3.5)$ & & $0.0023(0.015,0.0035)$ & & $4.2(3.9-4.6)$ & \\
\hline Wilczek & $6.6(3.5-12.2)$ & $4.2(1.8-9.0)$ & $0.818(0.48,0.97)$ & $0.71(0.29,0.96)$ & $2.3(1.6-3.1)$ & $1.4(0.9-2.1)$ \\
\hline Hwang & $4.6(2.2-9.5)$ & & $0.0046(0.0021,0.0091)$ & & $5.8(4.8-7.0)$ & \\
\hline Kelly & $8.6(6.2-11.9)$ & $5.2(3.4-7.9)$ & $0.92(0.78,0.98)$ & $0.73(0.51,0.89)$ & $2.2(1.8-2.7)$ & $1.3(1.0-1.7)$ \\
\hline Moon & $2.0(0.6-5.5)$ & & $0.0020(0.0005,0.0051)$ & & $31.1(29.1-33.2)$ & \\
\hline Huang & $7.9(5.2-12.0)$ & $9.2(6.3-13.5)$ & $0.95(0.78,0.99)$ & $0.85(0.67,0.95)$ & $10.5(9.4-11.7)$ & $3.5(2.9-4.2)$ \\
\hline Parris & $1.8(0.9-3.4)$ & & $0.0018(0.0009,0.0031)$ & & $3.3(2.8-3.8)$ & \\
\hline Brem & $6.2(5.0-7.6)$ & $5.4(4.3-6.7)$ & $0.91(0.81,0.97)$ & $0.6220(0.508,0.726)$ & $18.0(17.4-18.6)$ & $15.0(14.5-15.6)$ \\
\hline Girardi & $1.9(1.3-2.5)$ & & $0.0019(0.0013,0.0025)$ & & $1.9(1.7-2.1)$ & \\
\hline Shen & $2.0(1.2-3.5)$ & $1.2(0.5-2.4)$ & & & $0.3(0.2-0.5)$ & $0.2(0.1-0.3)$ \\
\hline Leong & $14.2(2.5-55.5)$ & & $0.0142(0.0017,0.050)$ & & $9.9(5.7-16.4)$ & \\
\hline Berg & $7.8(6.0-10.1)$ & $7.9(6.1-10.2)$ & $0.76(0.67,0.8488)$ & $0.6949(0.5613,0.8081)$ & $14.3(13.5-15.1)$ & $10.2(9.5-10.9)$ \\
\hline Hooley & $4.6(1.2-14.7)$ & & $0.0046(0.0010,0.0130)$ & & $23.6(20.4-27.1)$ & \\
\hline Ohuchi & $4.0(3.4-4.7)$ & $3.2(2.7-3.9)$ & $0.77(0.69,0.84)$ & $0.62(0.529,0.711)$ & $6.7(6.5-7.0)$ & $6.7(6.4-7.0)$ \\
\hline Corsetti & $4.4(3.1-6.3)$ & & $0.0044(0.003,0.0062)$ & & $5.5(5.0-6.0)$ & \\
\hline Dong & $1.9(1.5-2.5)$ & $2.6(2.1-3.3)$ & $0.34(0.39,0.69)$ & $0.47(0.3488,0.60)$ & $1.4(1.3-1.5)$ & $2.2(2.0-2.3)$ \\
\hline Youk & $22.4(11.4-42.2)$ & & $0.0004(0.0000,0.0014)$ & & $11.4(8.7-14.8)$ & \\
\hline Brancato & $0.4(0.1-1.5)$ & & $0.0030(0.0018,0.0046)$ & & $2.1(1.7-2.5)$ & \\
\hline
\end{tabular}


Table: 5 Biopsy rate and proportion of node negative invasive cancer diagnosed for ultrasonography VS Mammography imaging:

\begin{tabular}{|c|c|c|c|c|}
\hline Author & $\begin{array}{l}\text { Biospy ratio by } \\
\text { US }\end{array}$ & $\begin{array}{l}\text { Biopsy ratio by } \\
\text { MM }\end{array}$ & $\begin{array}{l}\text { Proportion of node negative invasive } \\
\text { cancer by US }\end{array}$ & $\begin{array}{l}\text { Proportion of node negative invasive } \\
\text { cancer by MM }\end{array}$ \\
\hline Honjo & - & - & $0.85(0.42,0.99)$ & $0.80(0.28,0.99)$ \\
\hline Tagliafico & $1.4(1.1-1.9)$ & - & $0.65(0.40,0.87)$ & - \\
\hline Weinstein & $3.5(2.2-5.5)$ & $3.3(2.1-5.1)$ & $1.000(0.29,1.000)$ & $1.000(0.29,1.000$ \\
\hline Kim & $4.6(3.9-5.4)$ & - & - & - \\
\hline Venturini & $1.2(0.6-2.3)$ & $0.8(0.5-1.4)$ & - & - \\
\hline Weigert & - & - & - & - \\
\hline Wilczek & $1.4(0.9-2.1)$ & $0.7(0.3-1.2)$ & - & - \\
\hline Kelly & $1.3(1.0-1.7)$ & $2.2(1.8-2.7)$ & - & - \\
\hline Moon & - & - & $0.500(0.012,0.98)$ & - \\
\hline Huang & - & - & - & - \\
\hline Parris & $3.3(2.8-3.8)$ & - & - & - \\
\hline Brem & $3.6(3.3-3.9)$ & $3.8(3.5-4.1)$ & - & $0.95(0.85,0.99)$ \\
\hline Girardi & $1.9(1.7-2.1)$ & - & - & - \\
\hline Shen & $0.2(0.1-0.4)$ & $0.1(0.0-0.2)$ & - & - \\
\hline Leong & $9.9(5.7-16.4)$ & - & - & - \\
\hline Berg & $6.7(6.1-7.3)$ & $2.2(1.9-2.5)$ & - & - \\
\hline Ohuchi & - & - & $0.73(0.62,0.83)$ & $0.79(0.70,0.863)$ \\
\hline Corsetti & $5.5(5.0-6.0)$ & - & - & - \\
\hline Dong & - & - & $0.533(0.31,0.72)$ & $0.522(0.34,0.71)$ \\
\hline Youk & $11.0(8.3-14.4)$ & - & - & - \\
\hline Brancato & $1.1(0.9-1.4)$ & - & - & - \\
\hline
\end{tabular}

Fig 2: Overall detection, recall and Biopsy rate of both methods

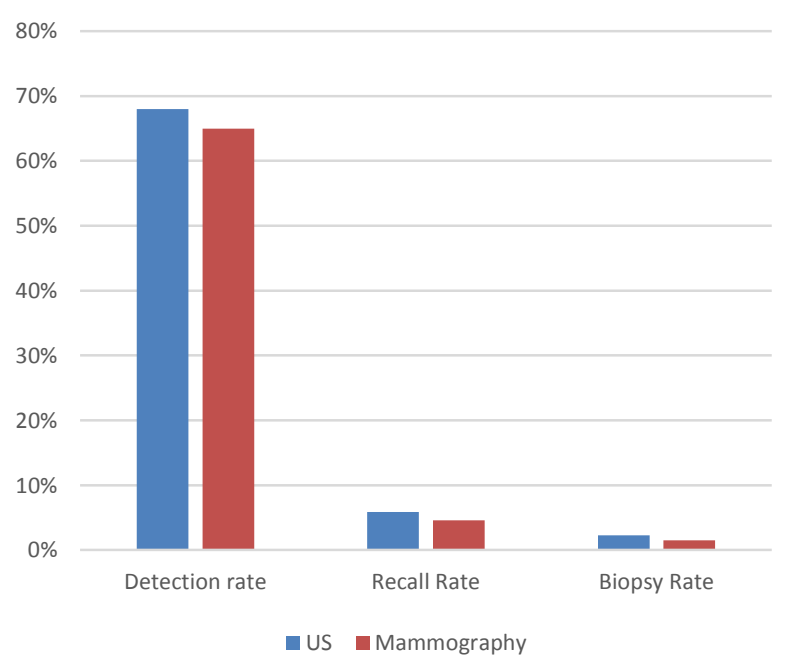

Figure 3: Forest plot of sensitivity and specificity difference of US and MM Imaging Vs US imaging alone

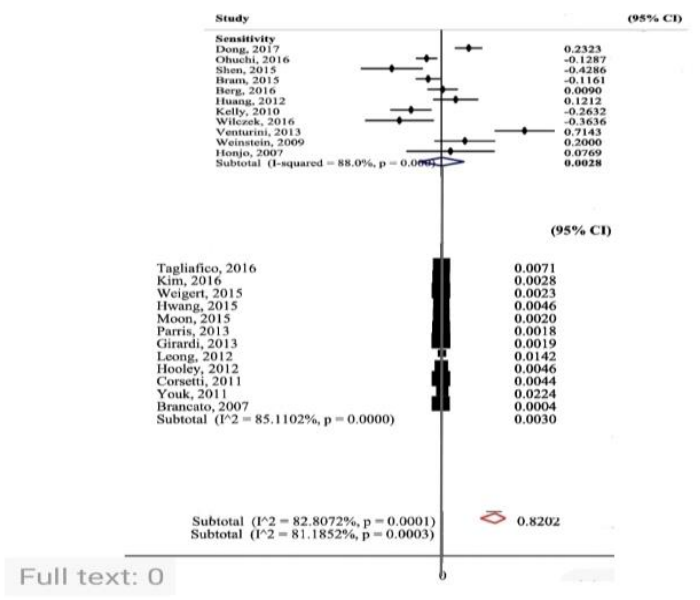

Table 6: Pooling data of sensitivity, specificity, recall rate and Biopsy rate.

\begin{tabular}{|l|l|l|}
\hline Variables & Pooled estimate \% & p value \\
\hline Sensitivity & 82.88 & 0.001 \\
\hline Specificity & 81.8 & 0.003 \\
\hline Recall Rate & 99.84 & 0.000 \\
\hline Biopsy rate & 98.94 & 0.000 \\
\hline
\end{tabular}

\section{DISCUSSION}

After the negative results of mammography, U.S. Preventive Services Task Force (USPSTF) had initiated the ultra sonographic techniques for evaluating the performance of screening among women with dense breasts. This process has been progressed in recent years with a high positive rate of screening and diagnosing breast cancer. In selected data of this study, the researchers failed to evaluate the breast cancer outcomes during screening. In 2013 Gartlehner ${ }^{33}$ produce a good systematic review of US screening along with mammography. His systematic review was based on the performance of both screening techniques separately ${ }^{33}$. In contrast, analysis of this study is focused on those researches which include both screening techniques at the same time. The selected data of this systematic review is based on those researches which initially failed to get positive results from mammography and then switched to ultra sonographic evaluation. Along with these researches, the relevant data is included related to ultra sonographic findings only. In this study, the performance of both screening methods is observed and their effectiveness is evaluated among patients. The data is collected from those researches which involve primary ultrasonography screening and supplemental ultrasonography screening.

In 2008, the role of supplemental Ultrasonography was highlighted by Berg ${ }^{4}$. According to Berg's observations, supplemental Ultrasonography has additional capacity to diagnose high-risk breast cancer women. In his study, he observed 1.1 diagnosing capacity through primary mammography and comparatively highlighted 7.2 cancer patients out of $1000^{4}$. In this analysis, 0.4 ratios of mammography screening capacity whereas 22.4 ultra 
sonographic capacity per 1000 examinations is found. This reflects the high performance of supplemental ultrasonography imaging ${ }^{11}$. This study is in favor of Berg's conclusion that ultrasonography should be considered as the primary technique for diagnosing breast cancer. However, there is no final consideration for initiating Ultrasonography imaging as a primary imaging guideline for breast cancer diagnosis. Contradictory researches made this decision more complex up till now. Different health sectors including the European Society of Breast Imaging (EUSOBI), the Japanese Breast Cancer Society, and the Chinese Anti-Cancer Association (CACA) are in the favor of supplemented ultra sonographic evaluation for the dense breasts ${ }^{34-36}$. According to them women with dense breasts has a high probability of negative mammography ${ }^{37-40}$.

On the other hand, many researchers claim that ultrasound also causes high recall issues and enhances the biopsy cases as compared to mammography. In this systematic review, this issue is also highlighted which is described in many pieces of research. Comparatively, no significant difference in biopsy rate between mammography and ultrasonography is found in this study. This could be due to the low sample size. Along with these issues, Ultrasonography also has several limitations which are major obstacles for initiating it as a primary imaging guideline. The ultrasound technique cannot take the whole image of the breast and failed to capture micro calcifications. These micro calcifications help to identify the tumor. Handling Ultrasonography is another major issue for its support. The operating procedure may fluctuate the results. Data selected for this study do not reflect any significant difference in sensitivity and specificity of US and mammography and no major difference is found in cancer characteristics and cancer detection ratio of selected studies while comparing both techniques. Comparatively, US has significantly high recall rate as compared to mammography. It is suggested that more studies regarding the US would be generated to observe the recall ratio among patients to remove the barriers for primary imaging. During the analysis, no significant difference regarding sensitivity and specificity among women with dense breasts and without dense breasts is observed. Through this analysis, long-term benefits of US imaging are not confirmed. More studies with long term follow up would be suggested to analyze the potential risks and long term benefits of both imaging techniques. The selected researches did not highlight the co-morbidities such as obesity which has a great influence on the screening process.

\section{CONCLUSION}

This study concludes that ultrasound is more efficient to diagnose factors suggestive of breast cancer that cannot be detected on mammography. It also has the potential to evaluate cancer among dense breast women but unfortunately in some cases, it may cause a high recall rate. Recommendations: It is suggested that more studies should be initiated to evaluate the performance of Ultrasonography in relation to other radiological modalities for early detection of breast cancer. Ultrasound has a potential to be used as a primary screening method for breast cancer. In many under resourced countries it would help to lessen the morbidity, if breast cancer is diagnosed at early stages.

\section{REFERENCES}

1. C, Akinyemiju TF, Al LF, et al. Global, regional, and National Cancer Incidence, Fitzmaurice Omortality, years of life lost, years lived with disability, and disability adjusted life-years for 29 Cancer groups, 1990 to 2016: a systematic analysis for the global burden of disease study. JAMA Oncol. 2018;4:1553-68.

2. Torre LA, Bray F, Siegel RL, et al. Global cancer statistics, 2012. CA Cancer J Clin. 2015;65:87-108.

3. Fan L, Strasser-Weippl K, Li J, et al. Breast cancer in China. Lancet Oncol. 2014;15:e279-89.

4. Berg WA, Blume JD, Cormack JB, et al. Combined screening with ultrasound and mammography vs mammography alone in women at elevated risk of breast cancer. JAMA. 2008;299:2151-63.

5. Boyd NF, Guo H, Martin LJ, et al. Mammographic density and the risk and detection of breast cancer. $\mathrm{N}$ Engl $\mathrm{J}$ Med. 2007;356:227-36.

6. Autier P, Boniol M, Koechlin A, Pizot C, Boniol M. Effectiveness of and over diagnosis from mammography screening in the Netherlands: population based study. BMJ. 2017;359:j5224.

7. Jorgensen KJ, Gotzsche PC, Kalager M, Zahl PH. Breast Cancer screening in Denmark: a cohort study of tumor size and Over diagnosis. Ann Intern Med. 2017;166:313-23.

8. Berg WA, Zhang Z, Lehrer D, et al. Detection of breast cancer with addition of annual screening ultrasound or a single screening MRI to mammography in women with elevated breast cancer risk. JAMA. 2012;307:1394-404.

9. Dong $\mathrm{H}$, Huang $\mathrm{Y}$, Song $\mathrm{F}$, et al. Improved performance of adjunctive ultrasonography after mammography screening for breast cancer among Chinese females. Clinl Breast Cancer. 2017;18:e353-61.

10. Ohuchi N, Suzuki A, Sobue T, et al. Sensitivity and specificity of mammography and adjunctive ultrasonography to screen for breast cancer in the Japan strategic anti-cancer randomized trial (J-START): a randomised controlled trial. Lancet. 2016;387:341-8.

11. Berg WA, Bandos AI, Mendelson EB, et al. Ultrasound as the primary screening test for breast cancer: analysis from ACRIN 6666. J Natl Cancer Inst. 2016;108:djv367.

12. Mclnnes $\mathrm{M}$, Moher $\mathrm{D}$, Thombs BD, et al. Preferred reporting items for a systematic review and meta-analysis of diagnostic test accuracy studies: the PRISMA-DTA statement. JAMA. 2018;319:388-96.

13. Honjo S, Ando J, Tsukioka T, et al. Relative and combined performance of mammography and ultrasonography for breast cancer screening in the general population: a pilot study in Tochigi prefecture, Japan. Jpn J ClinOncol. 2007;37:715-20.

14. Tagliafico AS, Calabrese M, Mariscotti G, et al. Adjunct screening with Tomo synthesis or ultrasound in women with mammography-negative dense breasts: interim report of a prospective comparative trial. J ClinOncol. 2016.

15. Weinstein SP, Localio AR, Conant EF, et al. Multimodality screening of high risk women: a prospective cohort study. J ClinOncol. 2009;27:6124-8.

16. Kim SY, Kim MJ, Moon HJ, Yoon JH, Kim EK. Application of the downgrade criteria to supplemental screening ultrasound for women with negative mammography but dense breasts. Medicine (Baltimore). 2016;95:e5279.

17. Venturini E, Losio C, Panizza P, et al. Tailored breast cancer screening program with microdose mammography, US, and 
MR imaging: shortterm results of a pilot study in 40-49-yearold women. Radiology. 2013; 268:347-55.

18. Weigert J, Steenbergen S. The Connecticut experiments second year: ultrasound in the screening of women with dense breasts. Breast J. 2015;21:175-80.

19. Wilczek B, Wilczek HE, Rasouliyan L, Leifland K. Adding 3D automated breast ultrasound to mammography screening in women with heterogeneously and extremely dense breasts: report from a hospitalbased, high-volume, single-center breast cancer screening program. Eur $\mathrm{J}$ Radiol. 2016;85:1554-63.

20. Hwang JY, Han BK, Ko EY, et al. Screening ultrasound in women with negative mammography: outcome analysis. Yonsei Med J. 2015;56:1352-8.

21. Kelly KM, Dean J, Comulada WS, Lee SJ. Breast cancer detection using automated whole breast ultrasound and mammography in radiographically dense breasts. EurRadiol. 2010;20:734-42.

22. Moon HJ, Jung I, Park SJ, et al. Comparison of Cancer yields and diagnostic performance of screening mammography vs. supplemental screening ultrasound in 4394 women with average risk for breast Cancer. Ultraschall Med. 2015;36:255-63.

23. Huang $\mathrm{Y}$, Kang $\mathrm{M}$, Li H, et al. Combined performance of physical examination, mammography, and ultrasonography for breast cancer screening among Chinese women: a followup study. CurrOncol. 2012;19: S22-30.

24. Parris T, Wakefield D, Frimmer $\mathrm{H}$. Real world performance of screening breast ultrasound following enactment of Connecticut bill 458. Breast J. 2013;19:64-70.

25. Brem RF, Tabar L, Duffy SW, et al. Assessing improvement in detection of breast cancer with three-dimensional automated breast US in women with dense breast tissue: the Somolnsight study. Radiology. 2015;274:663-73.

26. Girardi V, Tonegutti M, Ciatto S, Bonetti F. Breast ultrasound in 22,131 asymptomatic women with negative mammography. Breast. 2013;22:806-9.

27. Shen $S$, Zhou $Y, X u Y$, et al. A multi-Centre randomised trial comparing ultrasound vs mammography for screening breast cancer in high-risk Chinese women. $\mathrm{Br} J$ Cancer. 2015;112:998-1004.
28. Leong LC, Gogna A, Pant R, Ng FC, Sim LS. Supplementary breast ultrasound screening in Asian women with negative but dense mammograms-a pilot study. Ann Acad Med Singap. 2012;41:432-9.

29. Hooley RJ, Greenberg KL, Stackhouse RM, et al. Screening US in patients with mammographic ally dense breasts: initial experience with Connecticut public act 09-41. Radiology. 2012;265:59-69.

30. Corsetti V, Houssami N, Ghirardi M, et al. Evidence of the effect of adjunct ultrasound screening in women with mammography negative dense breasts: interval breast cancers at 1 year follow-up. Eur J Cancer. 2011;47: 1021-6.

31. Youk JH, Kim EK, Kim MJ, Kwak JY, Son EJ. Performance of hand-held whole breast ultrasound based on BI-RADS in women with mammographic ally negative dense breast. EurRadiol. 2011;21:667-75.

32. Brancato B, Bonardi R, Catarzi S, et al. Negligible advantages and excess costs of routine addition of breast ultrasonography to mammography in dense breasts. Tumori. 2007;93:562-6.

33. Gartlehner G, Thaler K, Chapman A, et al. Mammography in combination with breast ultrasonography versus mammography for breast cancer screening in women at average risk. Cochrane Database Syst Rev. 2013;4:D9632.

34. Tozaki M, Kuroki Y, Kikuchi M, et al. The Japanese breast Cancer society clinical practice guidelines for screening and imaging diagnosis of breast cancer, 2015 edition. Breast Cancer. 2016;23:357-66.

35. National Comprehensive Cancer Network. NCCN Clinical Practice Guidelines in Oncology (NCCN Guidelines):Breast Cancer Screening and Diagnosis. V1 ed.2016.

36. The Committee of Breast Cancer from the Chinese AntiCancer Association. Guidelines of diagnosis and treatment for breast Cancer by the Chinese anti-Cancer association (2017 edition). J Chin Oncol. 2017;27:695-760.

37. Evans A, Trimboli RM, Athanasiou A, et al. Breast ultrasound: recommendations for information to women and referring physicians by the European Society of Breast Imaging. Insights Imaging. 2018;9:449-61. 